\title{
Turning the Lens Around: LCA Success Stories Outside-In
}

\author{
Eric Mieras and Alain Wathelet
}

\begin{abstract}
Life Cycle Assessment experts are working on environmental assessments with both feet on the ground and faced every day with challenges around data quality, allocation and other challenging topics. But what's the perspective of the people that are the audience of the results: "How do they look at LCA?" The objective of this session was to show the value LCA has for people outside the LCA Community that are not as familiar with the topic as the Experts. Sanjeevan Bajaj (FICCI), Namy Espinoza-Orias (Nestlé), Pawin Boonyaporn (Advanced Biochemical), Jens-Christian Holst (Siemens) and Aubin Roy (AvniR) shared their experiences.
\end{abstract}

\section{Introduction}

Life Cycle Assessment (LCA) studies are often prepared by high level scientists and are focused on specific subjects for the interest of a small community. Nevertheless, the development of Life Cycle Thinking in a business organization leads to the use of a large panel of tools to demonstrate the sustainability of their business solutions (products and/or services), and an LCA approach perfectly fits this goal. During LCM, the benefits of this LCA approach are presented not only by LCA practitioners but also from the different users of Life Cycle approaches.

The "outside-in" session is conducted from the LCA perspective with a look from the perspective of users outside of the LCA community, including strategic decision making, marketing team, R\&I team and product development team.

E. Mieras $(\bowtie)$

PRé Sustainability, Stationsplein 121, 3818LE Amersfoort, The Netherlands e-mail: mieras@pre-sustainability.com

A. Wathelet

Solvay SA, 1120 Brussels, Belgium

(C) The Author(s) 2018

E. Benetto et al. (eds.), Designing Sustainable Technologies,

Products and Policies, https://doi.org/10.1007/978-3-319-66981-6_49 


\section{Internalizing Life Cycle Thinking in Business Strategy Through Amalgamation of Life Cycle Knowledge with Strategy Development Tools [1]}

Human societies today need business models that allow wealth generation along with regeneration of natural and social capital, which means going beyond the usual financial performance focus to manage environmental, social, developmental impacts of doing business. On top of this, Life Cycle approaches call for an assessment of these impacts not just from production and delivery, but across product/service life cycles from material extraction to end-of-life disposal. Given the dominant business paradigm of profit-maximization, why would business leaders succumb to hard sell by LCA practitioners and make life more complex for themselves?

To be fair, Life Cycle Thinking is not new to business management. The Value Chain concept is integral to business strategy. Based on a process view of organizations, the idea of seeing a business as a system, made up of subsystems with inputs, transformation processes and outputs is already internalized in strategy literature. How value chain activities are carried out determines costs and impacts profits. While converting inputs to outputs, business organizations engage in hundreds of activities which can be categorized as primary or support activities, and their depiction through the Value Chain diagram is pervasive in business management literature. Thus product development requires businesses to research where the raw materials might come from, which manufacturing processes may be needed, who will use the product, what additional costs will be incurred during use, what maintenance support will be needed, what types of waste will be created before/ during/after use, and where the product remnants will go when discarded. In the LCA practitioner's lingo, this translates to 'designers conduct life cycle studies and measure the potential impacts of various options, requesting information from suppliers, calculating full life cycle cost of goods consumers purchase including point-of-purchase price as well as costs of transporting, storing, installing, cleaning, operating, repairing, and eventually discarding those goods'.

Despite common ground across strategy development and Life Cycle approaches, there is little uptake of Life Cycle approaches at a truly strategic level. Most success stories about business value from Life Cycle studies talk about cost reductions through materials/energy saving, or customer loyalty through sustainability posturing. Cost reductions accompany operational improvements, while sustainability posturing builds image. Business leaders aren't fundamentally rethinking their business to increase aggregated well-being of the planet and human society. At best, they are trying to do less harm while going about their business.

For Life Cycle approaches to qualify as tools enabling paradigm shift, like Strategy tools, they must provide a structure to generate and evaluate strategic options of domain selection (what business to be in) and domain navigation (how to compete in this business). Business strategy deals with competition, business 
leaders choose the most attractive industries and/or influence industry structures to make them attractive for themselves.

The field of strategy is constantly evolving at a fast pace. LCA can be used to support strategic decision making for instance on which technology to invest in. However, most companies $(95 \%)$ do not include sustainability yet, so there's still a lot of companies to win.

\section{Integrated Product Development at Nestlé [2]}

At Nestlé, the world's largest nutrition, health and wellness company, the life cycle approach is applied to multi-criteria product innovation and renovation, which involves Nestlé's partners and stakeholders from farm to consumer and beyond.

In order to embed environmental sustainability into their products, the Sustainability by Design program led by the Research \& Development unit assesses and optimizes the environmental performance across the entire value chain at the earliest stages of product development. The identification of environmental hotspots where relevant, and the definition of actions to address them is carried out using the internal eco-design tool EcodEX. Furthermore, a new tool aimed at identifying opportunities for projects to deliver on Nestlé in Society commitments is being launched in 2017 across the R\&D organization.

On the other hand, successful product renovation and innovation requires building sufficient and necessary consumer, technical and product mastership knowledge. This consumer-centric approach entails the close cooperation of marketing, operations and R\&D units and also spans over the entire product life cycle.

This holistic and comprehensive methodology, as applied by Nestlé, delivers competitive advantage, leads to the fulfillment of public commitments at company level and drives the company contribution as member of the food industry to the achievement of the Sustainable Development Goals. Informed decision making takes place at the various steps of project execution, risks and opportunities are identified, and early warning is brought up at the appropriate time.

However, given the breadth of technical areas concerned and what is at stake, the interpretation of data and insights resulting from this way of working can be complex and raise some challenges. The deployment of support tools can only be justified as long as they are properly and widely used. Deciding which function will take up the identified actions for improvement, either R\&D, operations or both in a concerted way, requires alignment of objectives and priorities as well as clear allocation of resources. For a company as large as Nestlé, it is fundamental to progress from starting the conversation and raising awareness on multiple criteria for product development to consistently accomplishing it.

Being proactive and understanding that what matters to consumers entails all aspects of the product - going beyond quality and including sustainabilityenriches the product development process and provides consumers with a product they prefer, knowing that Nestlé has taken care of what matters to them. 
At Nestlé, LCA is one of the assessments used in a customer focused innovation approach. Nestlé created an overall dashboard for innovation decisions that is available for everyone involved. Within this multi-criteria assessment there's a clear role for LCA in combination with other impacts.

\section{Innovative Partnership to Promote Credible and Sustainable Bio-based Materials Through the Value Chain [3]}

Bio-based materials derived from plant residues open up exciting opportunities for environmentally-responsible products. Trendsetters such as bio-based epichlorohydrin $(\mathrm{ECH})$ can provide more sustainable alternatives for traditional raw materials. To this end, AkzoNobel, Advanced Biochemical (Thailand) Co., Ltd. (ABT) and EY (Ernst \& Young) have joined forces to develop a monitoring system which could track and quantify the use of renewable raw materials in paints, coatings and further applications. The partnership built on a previous agreement, whereby AkzoNobel would progressively increase the use of epoxy resins derived from Epicerol ${ }^{\circledR}$, a bio-based ECH, in its coatings products.

Throughout 2017, the partnership will roll out an online system which will support a comprehensive bio-based certification. ABT, AkzoNobel and EY have developed a 'chain of custody' methodology to ensure that even in situations where no physical segregation of petro and bio-based materials is practiced, volumes may still be assigned and reported.

Rather than buying ECH directly, AkzoNobel is sourcing epoxy resins from a number of intermediate producers. The company then uses epoxy resins as ingredients in various coatings. By creating market pull through e-certification, the partnership promotes bio-based materials through the value chain.

Epicerol $^{\circledR}$ is an ECH based on $100 \%$ renewable glycerine, a by-product from the transformation of vegetable oils. Manufactured by ABT using an innovative and patented process, the drop-in was developed and commercialised because of demand for a truly sustainable ECH.

A comparative Life Cycle Assessment (LCA) benchmarked Epicerol ${ }^{\circledR}$ against state-of-the-art propylene-based processes. It showed that incorporating 1 MT of Epicerol $^{\circledR}$ can reduce a product's carbon footprint (defined as the global warming potential (GWP) from cradle-to-gate, including biogenic $\mathrm{CO}_{2}$ ) by $2.56 \mathrm{MT} \mathrm{CO}_{2}$ equivalent.

The technology also reduces the volume of chlorinated by-products from the process by over $80 \%$, while another distinctive technology enables brine recycling and drastically reduces liquid effluents.

A wider rollout is targeted before end-2017. By promoting sustainable alternatives through pro-active procurement of bio-based feedstock and a transparent transfer of e-certificates across the value chain, this innovative project will demonstrate a credible approach to sourcing better materials. 


\section{The City Performance Tool-How Cities Use LCM Based Decision Support [4]}

Modern cities have an increasingly vital role to play in finding new ways to protect the environment. Understanding the environmental and economic impact of infrastructure choice is crucial for urban decision makers especially as linked to long term strategies and investment have to be taken. Siemens deep technology expertise can support this understanding however technology performance indicators have to be transformed to the solution embedded into a city specific context and in combination with other infrastructure choices across city domains.

Understanding these cities requirements and perspective of the decision makers Siemens developed the City Performance Tool to explore the environmental and economic impact of more than 70 technologies from Building, Transport and Energy Technologies - at different time periods and implementation rates.

It is designed to reduce the environmental impacts of everyday activities in cities. It covers greenhouse gas emissions from buildings and transport, as well as air pollutants such as particulate matter $(\mathrm{PM})$ and nitrogen oxides $\left(\mathrm{NO}_{\mathrm{x}}\right)$. It also looks at the creation of new local jobs to install, operate and maintain city solutions.

The common model determines the variety of activities in process blocks to build any city in a common LCA tool (SimaPro):

- $20+$ electricity and heat generation

- $10+$ building types its electricity, heat and cooling demand

- 10 freight modes; 35 passenger transport modes; 15 road and rail infrastructure elements

The CyPT provides environmental results relative to the amount invested. It enables city managers to prioritise projects based upon their likely environmental and economic impacts. It can offer city managers a roadmap towards meeting carbon emission targets, clean air standards and local job growth. The work presents the methodology, details about the underlying LCA models and its implementation into the tool. In transport, for example, CyPT assesses how a technology would reduce demand (reduce parking search traffic), shift the mode (public transport instead of cars) or improve efficiency (automated trains). The model is based on LCA methodology and builds upon Siemens' technology expertise and global databases of deep vertical process knowledge.

Now urban decision makers can use the City Performance Tool (CyPT) by Siemens to select urban infrastructure technologies that offer their own cities maximum environmental and economic benefits. The CyPT studies are performed in more than 25 cities worldwide and experiences gained will be shared in this presentation. 


\section{Implementing LCM All Along the Supply Chain: From Compliance to Collaborative Value Creation [5]}

In a complex society sustainable production and consumption patterns can only be achieved through the participation of entire supply chains, including designers, suppliers, manufacturers, etc. The involvement of all these actors and their collaboration is critical to mainstream LCM in a large scale and to create shared value. In this context, the aim of this contribution is to present the [avniR] "customer/ supplier" working group. In parallel, a set of success stories will be presented together with an assessment of challenges and opportunities to integrate LCM all along the supply chain.

Since 2012, a new governance based on different working groups was launched to strengthen collaboration within the [avniR] platform in North of France. A working group was initiated in this context to mainstream LCM all along the supply chain called "customer/supplier working group". Different actions were conducted in the context of the working group including awareness rising, workshops and collaborative working groups based on identified needs from the stakeholders.

One of the leading ongoing actions launched in collaboration with Renault, is the customer/supplier, Collaborative Life Cycle Activities (CoLCA). The first series of workshops was organized in 2016 with a large set of businesses both big and small ones. Seven businesses joined the working group (ALSTOM, FAVI, HAPPY CHIC, HELIOPAC, LE RELAIS-MÉTISSE, POLYNT COMPOSITES and SNCF).

As the first step, the "Collaborative Life Cycle Activities" approach was presented and discussed with participants. Then participant businesses conducted their own assessment internally involving various department (production, R\&D, top management, marketing, communication, etc.). A second meeting of the working group permit to present the self-maturity assessment results of each company and to discuss their plan to go to next level and begin interactions with their clients/ suppliers. In 2017 the working group aims to share and discuss the strategic plan and the learning from businesses involved, also to initiate the same dynamic with other businesses from variety of sectors.

As over $80 \%$ of a company's impact occur in the value chain, it's crucial to involve suppliers. Often these suppliers are SMEs that are less mature when it comes to environmental impact. Therefore, it's essential to involve them in the process. 


\section{References}

1. Bajaj S, Internalizing Life Cycle Thinking in Business Strategy through Amalgamation of Life Cycle Knowledge with Strategy Development Tools, LCM 2017 conference, Luxembourg, 2017.

2. Espinoza-Orias N, Cooper K, Integrated product development at Nestlé, LCM 2017 conference, Luxembourg, 2017.

3. Holst J.C, Heidinger K, Müller K, Jaeger F, The City Performance Tool- How cities use LCM based decision support, LCM 2017 conference, Luxembourg, 2017.

4. Boonyaporn P, Innovative Partnership to Promote Credible and Sustainable Bio-based Materials Through the Value Chain, LCM 2017 conference, Luxembourg, 2017.

5. Roy A, Adibi N, Pasquet V, Morel S, Implementing LCM all along the supply chain: from compliance to collaborative value creation, LCM 2017 conference, Luxembourg, 2017.

Open Access This chapter is licensed under the terms of the Creative Commons Attribution 4.0 International License (http://creativecommons.org/licenses/by/4.0/), which permits use, sharing, adaptation, distribution and reproduction in any medium or format, as long as you give appropriate credit to the original author(s) and the source, provide a link to the Creative Commons license and indicate if changes were made.

The images or other third party material in this chapter are included in the chapter's Creative Commons license, unless indicated otherwise in a credit line to the material. If material is not included in the chapter's Creative Commons license and your intended use is not permitted by statutory regulation or exceeds the permitted use, you will need to obtain permission directly from the copyright holder.

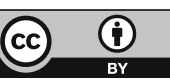

